\title{
Pentágono da qualidade na publicação acadêmica
}

\author{
Fábio Frezatti \\ https://orcid.org/0000-0002-5927-022X ｜ E-mail: frezatti@usp.br
}

\section{Motivação para o tema}

Um editor de revista acadêmica tem que decidir a sua estratégia para tratar a disponibilidade de artigos: escolhe o que acredita que seja promissor e descarta os demais artigos ou faz o contrário, ou seja, olha o que realmente não tem chances de ter conhecimento relevante e gasta tempo com o restante. Parece ser uma decisão tática, mas não é. Nem é simples de ser implementada. Nem deveria ser uma estratégia oportunista de curto prazo porque a comunidade tem uma inércia entre receber uma sinalização, se ajustar e reagir. A partir dessa decisão, apresentada nos seus extremos de aplicação, a carga de trabalho de todo o ecossistema editorial fica definida.

Quando nós, editores, erramos na etapa desk, apostando no artigo que não tem chances de ser aperfeiçoado, aumentamos a carga de trabalho dos revisores, autores e editores e isso, embora não fique capturado objetivamente, gera um desgaste desnecessário: profissionais que respeitamos e com os quais queremos ter relações de longo prazo pagam o preço.Avaliações dos erros do tipo 1 e do tipo 2 estão na nossa mente o tempo todo. De alguma forma, o produtivismo acadêmico afeta todo o ecossistema pressionando por quantidade de publicações (Miranda, Carvalho, \& Ramos, 2016), e a qualidade precisa ser traduzida de forma bem prática.

Em alguns casos, os revisores estranham a sugestão de uma rodada adicional quando eles recomendaram que o artigo seja rejeitado. Do lado do editor, ao olhar uma lista factível de ajustes, ele pode entender que proporcionar essa rodada adicional tem um custo-benefício em que a comunidade ganha. Nenhum editor quer perder um bom artigo, e os autores podem colaborar ao refletirem mais sobre o momento no qual o artigo esteja maduro para ser submetido com vistas à comunicação. Dependendo da atitude da comunidade, ter um artigo de boa qualidade sendo comunicado pode ser cada vez mais difícil de ser publicado (Trzesniak, Plata-caviedes\& Córdoba-Salgado, 2012), inclusive pela prematuridade da submissão.

Não quero enveredar pela discussão do que seria qualidade em termos de periódicos e associação com as citações, mas na estruturação e oferta dos artigos para a comunidade de maneira que esses tenham utilidade. Na verdade, de alguma forma, a geração do conhecimento deve melhorar a qualidade de vida dos seres humanos (Sabadini, Sampaio, \& Koeller, 2009). Isso é verdade em qualquer área de conhecimento, seja nas áreas ligadas à saúde das pessoas, seja na saúde das organizações, por exemplo. Zelar para que esse conhecimento chegue à comunidade é algo fundamental para todos.

Tenho visto na RC\&F muitos artigos promissores cujas promessas não se realizaram. Algumas possíveis respostas: "errei ao apostar", "os autores não se empenharam", "a comunicação do que fazer não foi eficiente etc.". Depois de passar por uma infindável lista de "etc.", quero estimular as ações as quais considero relevantes, por onde começar? 
Aperfeiçoar a comunicação é uma obra de arte, algo único para cada artigo. Deveria haver uma técnica de aperfeiçoamento do artigo que fosse, ao mesmo tempo, flexível e direcionadora. Não acredito em fórmula mágica, mas deveria haver algo que pudesse relacionar a experiência e o conhecimento de alguém com uma abordagem que aumentasse a eficiência, indicando o que deveria ser priorizado no processo. Em qualquer dimensão da atividade humana, pensamos, num primeiro instante, em inovação de ruptura, algo muito diferente, mas, em alguns casos, olhar o que já existe e aperfeiçoar isso pode ser uma maneira de proporcionar inovação efetiva e rápida. Quem sabe, com isso, poderíamos estimular novas contribuições ainda mais inovadoras e disruptivas?

\section{Dado o problema, existiria algo a ser feito por qualquer um de nós?}

Foi pensando na pergunta acima que surgiu o olhar para o conjunto dos cinco elementos que são utilizados total ou parcialmente por inúmeros periódicos como algo que é considerado nas análises, mas de forma absolutamente independente entre os vários elementos. O conjunto dos cinco elementos, que chamarei de pentágono, são: inovação, relevância, lacuna, contribuição e impacto. Tudo isso subordinado a um problema, que se apoia num construto para o desenvolvimento de uma pesquisa, em um dado campo.

Eles existem, mas em muitos casos são oferecidos pelos autores de maneira burocrática e não como brain de uma pesquisa desenvolvida de maneira criativa, séria e robusta e que deve ser comunicada da mesma forma. Frequentemente a lógica de comunicação se baseia na abordagem take for granted, como se fosse óbvio o seu entendimento, sem uma visão de facilitação e priorização do usuário fundamental, o leitor.

As definições de cada elemento passam por especificidades de cada área e mesmo dos periódicos, e o conjunto proporciona a figura do pentágono, que pode ser uma estrutura de apoio para alguma coisa. A pergunta provocativa seria: haveria oportunidade para utilizar de maneira mais eficiente esse conjunto de elementos?

Para responder à pergunta, algumas reflexões são necessárias:

\section{Quais as possíveis configurações do pentágono?}

Entendendo que a âncora de toda análise é o problema e, em algumas áreas, questão de pesquisa é oferecida, o pentágono pode ser utilizado como uma abstração de equilíbrio de elementos que podem proporcionar a qualidade intrínseca de uma pesquisa ao lidar com o construto teórico, o campo e a metodologia.

Várias possibilidades se apresentam e a Figura 1 contém, no centro, o sonho de consumo dos editores, ou seja, um pentágono com destaque para todos os elementos. Em outras palavras, uma comunicação de pesquisa que tem uma lacuna clara, uma inovação perceptível tratando de um tema relevante que se constitui em contribuição esclarecida, impactando a sociedade em alguma dimensão. Fácil ter sucesso, não é? Parece que não é tão fácil, e os formatos dos pentágonos nos quatro lados da Figura 1 ilustram as alternativas. 

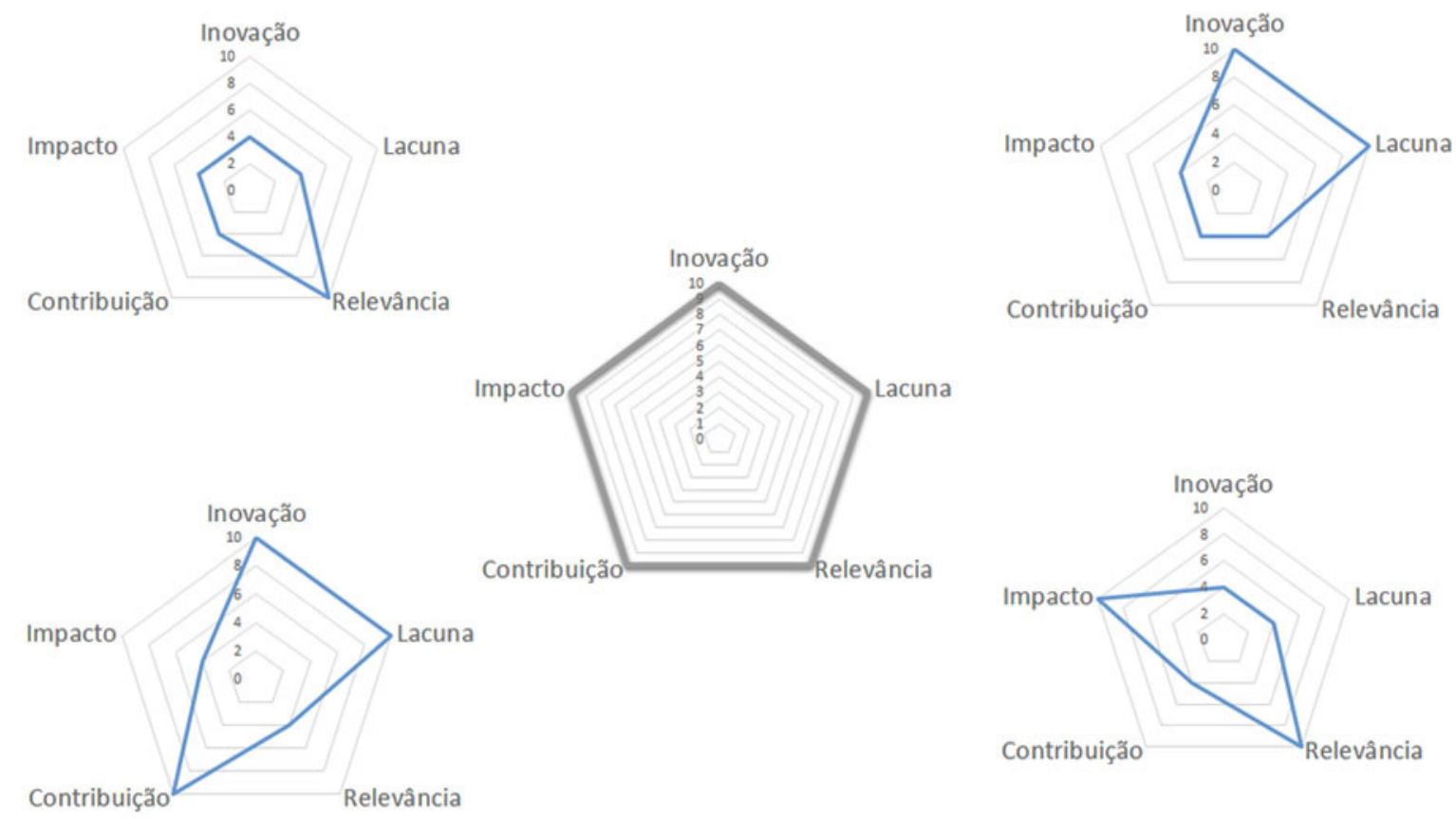

Figura 1. Várias formas de encontrar o pentágono da qualidade numa comunicação acadêmica.

Tente lembrar-sede um artigo sobre um tema extremamente relevante, mas sem nenhuma inovação. Ou, então, de outro artigo em que a lacuna ficou evidenciada, mas seja de baixa relevância e, consequentemente, baixo impacto. Que tal a pesquisa com potencial de alta relevância e alto impacto, mas que, por falta de aprofundamento, aparenta uma lacuna inexpressiva e, desse modo, inovação pouco relevante?

$\mathrm{O}$ artigo pode apresentar fragilidades nesses mesmos elementos e, no lugar de simplesmente ser rejeitado, pode ser aprimorado em diferentes momentos da construção do conhecimento, desde que os autores percebam onde e como ajustar suas comunicações de pesquisa.

Acredito que você tenha percebido que a oportunidade está ligada à evidenciação do pentágono. Os elementos podem até existir de forma bem adequada, mas você, autor, deve preocupar-se em mostrálos para os agentes que proporcionam a comunicação acadêmica.

\section{Como o pentágono poderia ser utilizado?}

Duas vertentes com grande potencial de benefício: a) relacionamento entre os elementos e b) dinamismo do processo.

A primeira vertente significa dizer que rever a lacuna, por exemplo, não corresponde a simplesmente dizer que nada foi escrito no Brasil sobre o tema. Ao contrário, ao evidenciar o que foi comunicado sobre o tema, deixar claro o que não foi pesquisado, o que não se sabe, bem como especificar a lacuna e propor reduzi-la ou eliminá-la, a inovação fica evidenciada. Essa inovação é a maneira como podemos evidenciar a contribuição, a qual pode não eliminar toda a lacuna, mas é relevante até para que outros pesquisadores possam se apoiar e trazer suas contribuições. Ao final, entendendo a contribuição, podemos perceber o impacto que o novo conhecimento gera na sociedade, em algum tipo de dimensão, seja econômica, social ou cultural, ou mesmo em todas. Esse relacionamento exige algum nível de abstração e de aproximação com o campo, fortalecendo a avaliação do artigo. 
Por sua vez, a vertente do dinamismo está ligada ao compromisso de aprimorar o trabalho, percorrendo os elementos várias vezes e identificando nas mudanças dos elementos novas oportunidades de aperfeiçoamento. Como exemplo disso, ao aperfeiçoarmos a expressão da lacuna, pontos adicionais de inovação, conceituais e empíricos, novas contribuições podem ser identificadas e, com isso, a pesquisa pode proporcionar impacto ainda maior.

Se o indivíduo não estiver satisfeito com a melhoria do trabalho, deve tentar de novo, quem sabe uma ou duas semanas depois, se a circunstância vivenciada por ele permitir. O dinamismo do aperfeiçoamento é algo que pode ser percebido se o autor se dispuser a aperfeiçoar o trabalho e talvez mais de uma rodada proporcione benefícios bem significativos.

\section{Quando usar o pentágono}

Olhando para os trabalhos que tenho oportunidade de analisar, a utilização do raciocínio do pentágono no momento da concepção e implementação dos projetos seria muito útil. Ao levarem-se em conta de maneira intensa esses elementos, haveria um grande benefício para toda a comunidade, pois algumas mudanças podem ser inviáveis se ocorrerem após o trabalho de campo.

Entretanto, olhar um artigo pronto e analisar seus pontos fortes e fracos quanto à comunicação, atende minha demanda motivacional principal na perspectiva editorial.

\section{Comentários finais}

O objetivo deste editorial foi instigara reflexão e análise crítica da comunidade, apoiando e/ou questionando a proposta. Se a abordagem fizer sentido, tente utilizá-la do seu jeito. Pesquisas podem ser feitas para validar ou não tal proposta. Entender que condições podem ser oferecidas para delimitar, contestar ou ampliar a abordagem também se mostra fundamental. Teste e conclua você mesmo.

Estou inconformado com o status quo e a perda de eficiência de trabalhos que poderiam ser mais valorizados, se adequadamente burilados. Não se trata apenas de ter artigos aceitos em periódicos acadêmicos, mas da sua longevidade. Afinal, a comunicação não é o fim, mas o início do impacto de uma pesquisa que será utilizada por alguém. Pense nisso, porque a utilidade por longo prazo faz toda a diferença. Na sua vida e na da comunidade. O compromisso do autor com o artigo deveria ser de longo prazo, e a qualidade intrínseca pode ser um fator importante para que o seu artigo, além de ser aceito e publicado em um periódico disputado, tenha uma vida útil longa: vida longa ao artigo!

A responsabilidade por esse trabalho deve partir dos autores, embora apoiada pelos revisores e editores. Um trabalho mais criterioso por parte dos autores beneficiaria todo o ecossistema, inclusive eles mesmos; esses, no mínimo, com uma significativa redução de prazo de publicação. Não precisaremos de duas, três, quatro ou cinco revisões, se os trabalhos vierem mais amadurecidos. Isso sempre foi dito, mas aqui se propõe uma possível abordagem sobre como fazê-lo.

Algumas pessoas acreditam que modelos podem responder a todas as questões e eliminar problemas como em um passe de mágica. Má notícia: não fazem isso. Podem aumentar a eficiência e, eventualmente, aumentar a chance de sucesso de uma pesquisa que, de outra forma, não o teria. Ao final, o que ocorre é que continuamos dependendo do talento, da motivação e do compromisso do principal ingrediente do processo editorial: o ser humano. A técnica existe para tornar a vida mais fácil e eficiente e, alargando a expectativa, fazendo as pessoas mais felizes. Só isso. 


\section{Referências}

Miranda, A. C. C. de, Carvalho, A. V., \& Ramos, A. S. M. (2016). Comunicação científica em administração (Scientific communication in Administration). Revista Ciências Administrativas, 22(2), pp. 573-604. Doi: https://doi.org/10.5020/2318-0722.22.2.573-604

Sabadini, A. A. Z. P., Sampaio, M. I. C., \& Koeller, S. H. (2009). Publicar em Psicologia. (A. B. de E. C. de Psicologia, Ed.). São Paulo: Instituto de Psicologia da Universidade de São Paulo.

Trzesniak, P., Plata-caviedes, T., \& Córdoba-Salgado, O. A. (2012). Qualidade de conteúdo, o grande desafio para os editores científicos. Revista Colombiana de Psicología, 21(1), pp. 57-78. Recuperado em: https://www.redalyc.org/articulo.oa?id=80424036005 